\title{
Exogenous Spermidine Inhibits Ethylene Production in Leaves of Cucumber Seedlings under NaCl Stress
}

\author{
Bin $\mathrm{Li}^{1}$, Ting Sang ${ }^{1}$, Lizhong He, Jin Sun, Juan Li, and Shirong Guo ${ }^{2}$ \\ Key Laboratory of Southern Vegetable Crop Genetic Improvement in Ministry of Agriculture, \\ College of Horticulture, Nanjing Agricultural University, Nanjing 210095, P.R. China; Academy of \\ Protected Horticulture, Nanjing Agricultural University (Suqian), Jiangsu Suqian 223800, China
}

\begin{abstract}
AdDitional INDEX words. salinity, polyamine, ACC, ACO
Abstract. To examine whether $1 \mathrm{~mm}$ of spermidine (Spd) modifies plant ethylene production in response to shortterm salt stress, cucumber (Cucumis sativus) seedlings were grown in nutrient solution with or without $75 \mathrm{~mm} \mathrm{NaCl}$ stress for 3 days, and the leaves were sprayed with $1 \mathrm{~mm}$ Spd or water (control). We investigate the effects of the treatments on ethylene production, 1-aminocyclopropane-1-carboxylate (ACC) content, 1-(malonylamino) cycolpvopane-1-carboxylic acid (MACC) content, activities of 1-aminocyclopropane-1-carboxylate synthase (ACS), and 1-aminocyclopropane-1-carboxylate oxidase (ACO) and gene expression of acs2, aco1, and aco2 in the cucumber leaves. The results indicate that ethylene production was increased significantly under salt stress as did ACC and MACC content, the activities of ACS and ACO, and the transcriptional level of acs2, whereas the gene expression of aco1 and aco2 was somewhat decreased. However, exogenous Spd treatment depressed the content of ACC and MACC, ACS activity, and the level of acs 2 transcripts in the leaves of salt-stressed cucumber. Although the activity of ACO and gene expressions of aco1 and aco2 increased by Spd, ethylene emission was inhibited. Our results suggest that application of exogenous Spd could reverse salinity-induced ethylene production by inhibiting the transcription and activity of ACS under salt stress. We conclude that exogenous Spd could modify the biosynthesis of ethylene to enhance the tolerance of cucumber seedlings to salt stress.
\end{abstract}

Salt stress poses a major environmental threat to agricultural production. At high concentrations of salts in the soil, plants experience a physiological drought because of the inability of roots to extract water, and high concentrations of salts within the plant can be toxic (Munns and Tester, 2008). When plants are exposed to environmental stresses, plants typically synthesize increased levels of the phytohormone ethylene and are often unable to grow and proliferate to any great extent, at least until the stress is removed and the ethylene level is lowered (Gamalero and Glick, 2012). Various biotic and abiotic stresses can cause an imbalance in ethylene production, and increased ethylene levels can cause leaf senescence and inhibit root elongation and overall plant growth (Bacilio et al., 2004; Cheng et al., 2007; Klassen, 2002; Mayak et al., 2004; Zahir et al., 2009).

There are several steps in ethylene biosynthesis. Two of the most important biosynthetic enzymes are 1-aminocyclopropane1-carboxylate synthase, which controls production of 1-aminocyclopropane-1-carboxylate, and 1-aminocyclopropane-1carboxylate oxidase, controlling oxidative degradation of ACC. ACC is the immediate precursor of ethylene, and it is converted by S-adenosylmethionine (SAM). Some ACC is conjugated with malonate to form 1-(malonylamino) cyclopvopane-1-carboxylic acid, which cannot be converted back to ACC. The formation of ACC is often cited as the rate-limiting step in ethylene biosynthesis (Kende, 1993), and lower accumulation of ACC

Received for publication 5 Oct. 2012. Accepted for publication 27 Dec. 2012. This work was supported by the National Natural Science Foundation of China (No. 30900995; 31071831; 31272209), the National Basic Research Program of China (973 Program, No. 2009CB119000), the Priority Academic Program Development of Jiangsu Higher Education Institutions (PAPD), and the China Earmarked Fund for Modern Agro-industry Technology Research System (CARS-25-C-03).

${ }^{1}$ These authors contributed equally to this work.

${ }^{2}$ Corresponding author. E-mail: srguo@njau.edu.cn. diminishes the negative effects of stress-induced ethylene, resulting in better plant growth (Penrose and Glick, 2001).

Polyamines (PAs) are low-molecular-weight aliphatic amines that are ubiquitous in all organisms. Common natural PAs include the higher PAs, spermine (Spm) and spermidine, and their diamine obligate precursor putrescine. In plants, PAs have been implicated in many physiological processes such as organogenesis, embryogenesis, floral initiation and development, leaf senescence, fruit development and ripening, and abiotic and biotic plant stress responses (Alcazar et al., 2006; Bagni and Tassoni, 2001; Bouchereau et al., 1999; Galston and Sawhney, 1990; Kumar et al., 1997; Kusano et al., 2008; Malmberg et al., 1998; Walden et al., 1997). PAs and ethylene biosynthetic pathways share the same precursor, SAM (Slocum et al., 1984). Therefore, there may be an antagonistic relationship between biosyntheses of these two types of compounds. PAs can inhibit biosynthesis of ethylene in higher plant tissues and fruit protoplasts (Apelbaum et al., 1981; Roberts et al., 1984). However, in another study, there was no competition between PAs and ethylene biosyntheses (Mathooko et al., 1995).

Cucumber is one of the most important vegetables worldwide. It is highly sensitive to salinity, especially its germination and early growth phases (Baysal and Tipırdamaz, 2004). It has been showed that exogenous Spd can improve salt tolerance in cucumber (Du et al., 2010; Duan et al., 2008). Little is known about the effects of exogenous PAs on ethylene production in cucumber seedlings under salt stress. Therefore, we investigated whether an exogenous PA, Spd, could modify ethylene production and enhance growth and salt tolerance of cucumber seedlings.

\section{Materials and Methods}

Plant material and stress treatments. Cucumber (cv. Jinchun No. 2) seeds were germinated on moist filter paper in 
the dark at $28{ }^{\circ} \mathrm{C}$ for $30 \mathrm{~h}$. The germinated seedlings were transferred to plastic trays $(41 \times 41 \times 5 \mathrm{~cm})$ containing quartz sand and were grown in a greenhouse at Nanjing Agricultural University at 25 to $30{ }^{\circ} \mathrm{C}$ (day) and 15 to $18{ }^{\circ} \mathrm{C}$ (night) under natural light with relative humidity of $60 \%$ to $75 \%$. When the cotyledons had expanded, seedlings were supplied with water containing half-strength Hoagland's nutrient solution, and the solution was renewed every $2 \mathrm{~d}$. The nutrient solutions were kept at 20 to $25^{\circ} \mathrm{C}$ and were continuously aerated using an air pump at an interval of $20 \mathrm{~min}$ to maintain the dissolved oxygen at $8.0 \pm 0.2 \mathrm{mg} \cdot \mathrm{L}^{-1}$.

After $3 \mathrm{~d}$ of pre-culture, the cucumber seedlings were treated as follows: 1) control plants were grown in Hoagland's solution and the leaves were sprayed with $\mathrm{H}_{2} \mathrm{O}(\mathrm{C}) ; 2$ ) plants were grown in Hoagland's solution and the leaves were sprayed with $1 \mathrm{~mm}$ Spd (CS); 3) plants were grown in Hoagland's solution containing $75 \mathrm{~mm} \mathrm{NaCl}$ and the leaves were sprayed with $\mathrm{H}_{2} \mathrm{O}$ (S); and 4) plants were grown in Hoagland's solution containing $75 \mathrm{~mm} \mathrm{NaCl}$ and the leaves were sprayed with $1 \mathrm{~mm} \mathrm{Spd}$ (SS). The leaves of the control and salt-treated plants were sprayed with distilled water or $1 \mathrm{~mm}$ Spd (Sigma-Aldrich, St. Louis, MO) containing Tween-20 (0.5\%, v/v; Haijiechem, Zibo, China) as the detergent. Three $d$ after the beginning of the $\mathrm{NaCl}$ treatment, the fully expanded third leaves were collected to analyze ethylene production, ACC and MACC content, enzyme activities, and gene expression.

Analysis of Ethylene production. After fresh weights were determined, the leaves were placed adaxially on watermoistened filter papers. The papers were rolled cylindrically and placed into glass tubes, which were then sealed with silicone septa. After incubation at room temperature for $2.5 \mathrm{~h}$ in the dark, 1-mL gas samples were withdrawn with a syringe and then injected into a gas chromatograph (GC5890; Kejie, Nanjing, China). Ethylene production is expressed as nanomoles per gram fresh weight per hour.

Determination of ACC and MACC content. ACC and MACC were extracted according to An et al. (2006). The sample of fresh leaf tissue $(5 \mathrm{~g})$ was homogenized in $10 \mathrm{~mL}$ $95 \%$ ethanol and the mixture centrifuged at $10,000 g_{n}$ for $10 \mathrm{~min}$. The supernatants were kept and pellets were further extracted with $10 \mathrm{~mL} 80 \%$ ethanol. After centrifugation, the supernatants were combined and evaporated to dryness. The resulting residues were suspended in $1 \mathrm{~mL}$ chloroform and vortexed for $30 \mathrm{~s}$ to remove the pigments and then dissolved in $2 \mathrm{~mL}$ double-distilled water. The resulting suspensions were centrifuged at $4000 \mathrm{~g}_{\mathrm{n}}$ for $5 \mathrm{~min}$; the ACC was in the water phase. To measure the ACC content, $40 \mu \mathrm{L} 0.25 \mathrm{mM} \mathrm{HgCl}_{2}$ was added to $0.5 \mathrm{~mL} \mathrm{ACC}$ extract containing $5.5 \% \mathrm{NaOCl}$ and saturated $\mathrm{NaOH}(2: 1, \mathrm{v} / \mathrm{v})$ and shaken in an ice/water bath for $40 \mathrm{~min}$. Then, a 1-mL gas sample was withdrawn with a syringe from each test tube, and the gas sample was injected into a gas chromatograph. The ACC content was calculated on the basis of ethylene production using the method of Concepcion et al. (1979). The MACC content was determined according to the method of Hoffman et al. (1982).

Assay of ACS ACTivity. ACS enzyme activity was assayed according to Moeder et al. (2002). Leaf tissues ( $0.5 \mathrm{~g})$ were ground in liquid $\mathrm{N}_{2}$ and extracted with $1 \mathrm{~mL} 0.1 \mathrm{M} 3$-[4(hydroxyethyl)-1-piperazine base] propionic acid (EPPS; Sigma-Aldrich) buffer, $\mathrm{pH} 8.5$, containing $5 \mathrm{~mm}$ dithiothreitol, $5 \mu \mathrm{M}$ pyridoxal phosphate, and protease inhibitors $(500 \mu \mathrm{M}$ phenylmethylsulfonyl fluoride and $10 \mu \mathrm{M}$ leupeptin). After the addition of water-insoluble polyvinylpolypyrrolidone $(2 \%, \mathrm{w} / \mathrm{v})$ and vortexing for $10 \mathrm{~s}$, the extract was centrifuged at $20,000 \mathrm{~g}$ for $10 \mathrm{~min}$ at $4{ }^{\circ} \mathrm{C}$. The supernatant was gel-filtered on a Sephadex G-25 (Shoude, Nanjing, China) column equilibrated with $5 \mathrm{~mm}$ EPPS (pH 8.5), 1 mM DL-dithiothreitol, $5 \mu \mathrm{M}$ pyridoxal phosphate, and protease inhibitors. The protein content of the extracts was determined according to the method of Bradford (1976), and then all extracts were adjusted to the same protein concentration. Activity of ACS was assayed in glass flasks containing $0.4 \mathrm{~mL}$ protein extract and final concentrations of $80 \mathrm{~mm}$ EPPS ( $\mathrm{pH} 8.5), 20 \mu \mathrm{M}$ pyridoxal phosphate, and $100 \mu \mathrm{M}$ SAM (Shenggong, Shanghai, China) in a total volume of $0.5 \mathrm{~mL}$ at $30{ }^{\circ} \mathrm{C}$ for $2 \mathrm{~h}$. Blanks omitting SAM were incubated in parallel. The reaction was stopped by adding $100 \mu \mathrm{L} 10 \mathrm{~mm} \mathrm{HgCl}_{2}$ on ice. ACC was converted to ethylene as described previously, and $1 \mathrm{~mL}$ of the gas was analyzed by gas chromatography. Activity of ACS is expressed as nanomoles ACC per gram protein per hour.

Assay of ACO ACTIVITY. ACO enzyme activity was assayed according to Kato et al. (2000). Leaves (0.5 g) were homogenized in $1 \mathrm{~mL}$ extraction buffer consisting of $0.1 \mathrm{M}$ Tris- $\mathrm{HCl}$, $\mathrm{pH} 7.5,5 \mathrm{~mm}$ dithiothreitol, $30 \mathrm{~mm} \mathrm{Na}$-ascorbate, and 10\% glycerol $(\mathrm{v} / \mathrm{w})$ at $4{ }^{\circ} \mathrm{C}$. The homogenate was centrifuged at $14,000 \mathrm{~g}$ for $20 \mathrm{~min}$ at $4^{\circ} \mathrm{C}$. The protein content of supernatants was determined and then all extracts were adjusted to the same protein concentration. ACO activity was measured as described previously (Kato and Hyodo, 1999) and is expressed as micromole ethylene per gram protein per hour.

RT-PCR Assay. Total RNA was extracted from leaves using the Trizol reagent protocol (Takara Bio, Shiga, Japan). For all samples, total RNA $(1 \mu \mathrm{g})$ was converted to cDNA using the Superscript first-strand synthesis system for reverse transcription-polymerase chain reaction (PCR) according to the manufacturer's instructions (Takara Bio). Primers were designed according to sequences obtained from National Center for Biotechnology Information and a cucumber database (Huang et al., 2009). The following primers were used for amplifications: for acs $2, \mathrm{~F}: 5^{\prime}$-ATGGGAAAAGTGAGA GGGA-3' and A:5' -AAGACAGTGGCAGCGTAGA -3' ; for acol, F:5' -TGGCTGTCTTTCCTATCA-3' and A:5'-CGTCC AGTTCCACTTGTT-3'; for aco 2, F:5' -CACCTTGTCCAAAC CCAG-3' and A:5'-TTCATTTTTCTCCTCCGC-3'; and for actin, F:5'-CTGCTGTGCATTGGCTCTAACACC-3' and A:5'-GGAACTGCTCTTTGCAGTCTCGAG -3'. The PCR conditions were optimized for each primer set. PCR amplification was carried out after denaturing cDNA at $94^{\circ} \mathrm{C}$ for $5 \mathrm{~min}$ followed by 35 cycles of $94^{\circ} \mathrm{C}$ for $30 \mathrm{~s}$, annealing temperature for $30 \mathrm{~s}$, and extension at $72{ }^{\circ} \mathrm{C}$ for $35 \mathrm{~s}$. The final PCR extension step was at $72{ }^{\circ} \mathrm{C}$ for $7 \mathrm{~min}$. The amplified cDNA fragments were detected using agarose gel electrophoresis.

\section{Results}

ETHYLENE PRODUCTION. Ethylene production increased by $142.67 \%$ in leaves of salt-stressed plants compared with that of the control. Exogenous Spd reduced salinity-induced ethylene production by $29.78 \%$, but it did not significantly affect ethylene production in plants grown in Hoagland's solution (Fig. 1).

ACC And MACC Content. Compared with the control, ACC and MACC content in the cucumber leaves increased significantly by $108.18 \%$ (Fig. 2A) and $42.6 \%$ (Fig. 2B), respectively, 


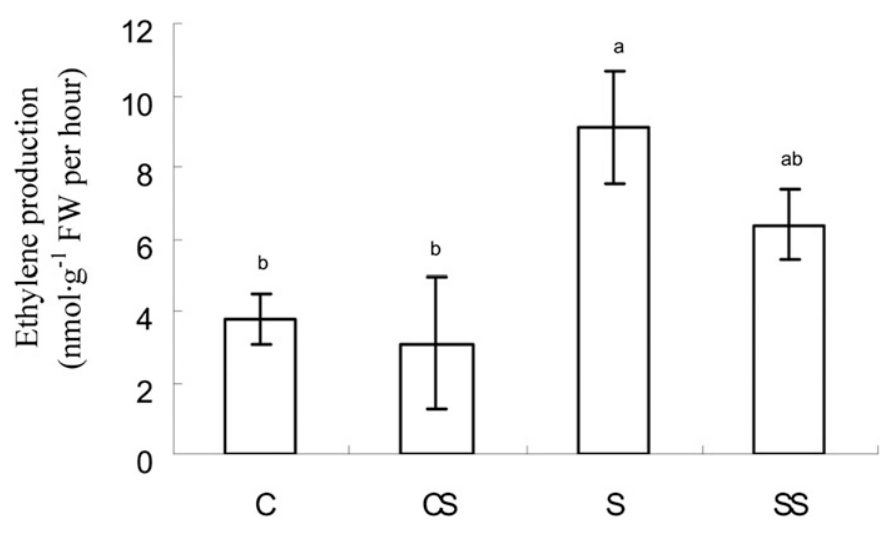

Fig. 1. Effect of salt stress and/or exogenous application of $1 \mathrm{~mm}$ spermidine (Spd) on ethylene production in leaves of cucumber seedlings after 3-d treatments. $\mathrm{C}=$ control; $\mathrm{CS}=$ control + Spd foliar spray; $\mathrm{S}=75 \mathrm{~mm} \mathrm{NaCl} ; \mathrm{SS}=75 \mathrm{~mm}$ $\mathrm{NaCl}+\mathrm{Spd}$ foliar spray. Values shown are means of three independent experiments. Different letters indicate significant differences (Duncan's multiple range test at $P<0.05)$. under salt stress. Exogenous Spd reduced salinity-induced ACC and MACC content by $34.93 \%$ (Fig. 2A) and $48.01 \%$ (Fig. 2B), respectively, but it did not significantly affect ACC content in leaves of plants grown in normoxic nutrient solution (Fig. 2A). Exogenous Spd decreased the MACC content by $39.82 \%$ in normoxic nutrient solution compared with the control (Fig. 2B)

ACS AND ACO ACTIVITIES. The activities of ACS and ACO in the leaves were markedly increased under salt stress compared with the control (Fig. 3). Exogenous Spd reduced ACS activity by $43.03 \%$ under salt stress, whereas it did not significantly affect its activity in plants grown in normoxic nutrient solution (Fig. 3A). However, exogenous Spd increased ACO activity by $165.8 \%$ in plants grown in normoxic nutrient solution and by $59.2 \%$ in plants under salt stress (Fig. 3B).

EXPRESSIONS OF GENES ENCODING ACS AND ACO. Expression of acs 2 was up-regulated in salt-stressed cucumber leaves, whereas exogenous Spd decreased its transcription in plants in
(A)

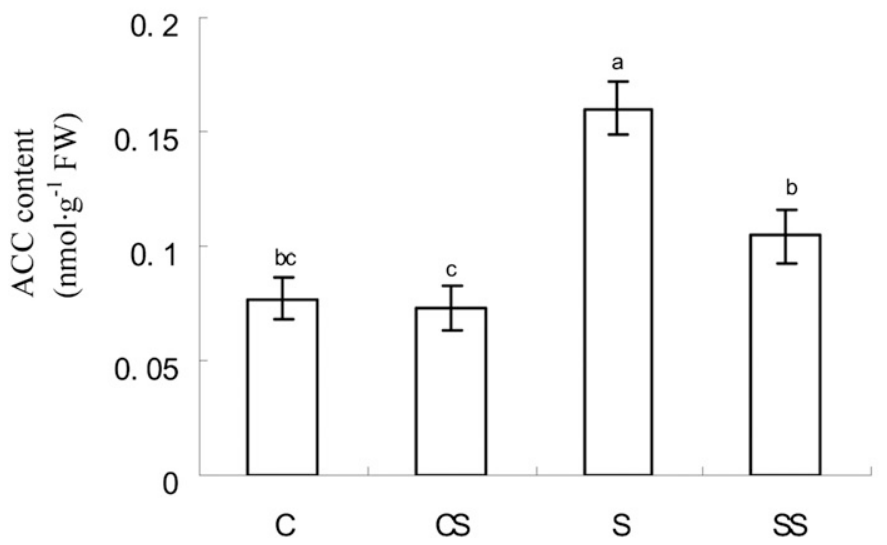

(B)

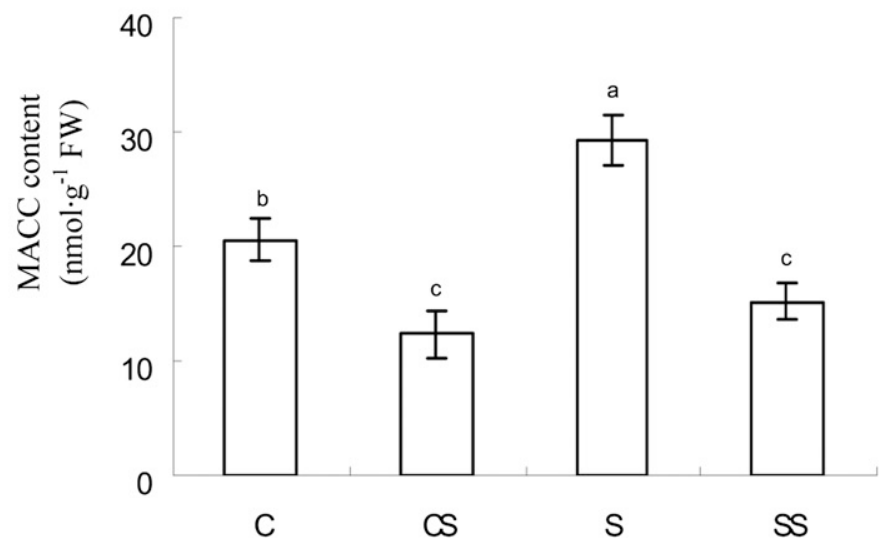

Fig. 2. Effect of salt stress and/or exogenous application of $1 \mathrm{~mm}$ spermidine (Spd) on the content of (A) 1-aminocyclopropane-1-carboxylate (ACC) and (B) 1-(malonylamino) cycolpvopane-1-carboxylic acid (MACC) in leaves of cucumber seedlings after 3-d treatments. C $=$ control; $C S=c o n t r o l+S p d$ foliar spray; $\mathrm{S}=75 \mathrm{~mm} \mathrm{NaCl} ; \mathrm{SS}=75 \mathrm{~mm} \mathrm{NaCl}+$ Spd foliar spray. Values shown are means of three independent experiments. Different letters indicate significant differences (Duncan's multiple range test at $P<0.05$ ).
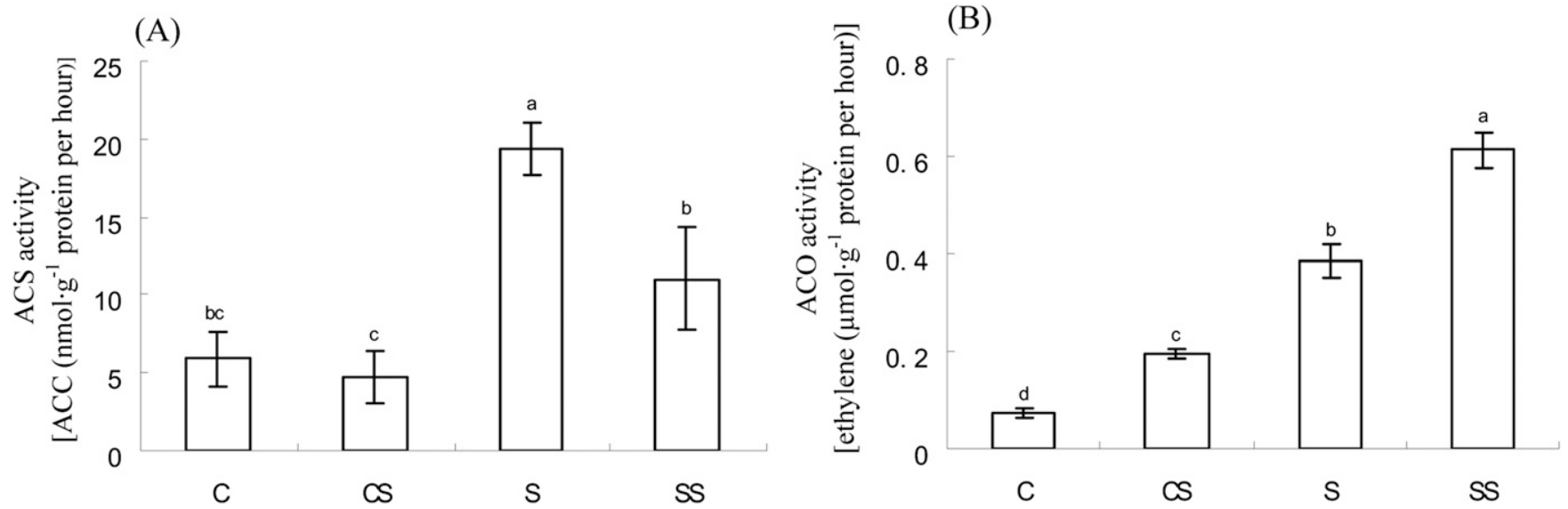

Fig. 3. Effect of salt stress and/or exogenous application of $1 \mathrm{~mm}$ spermidine (Spd) on (A) 1-aminocyclopropane-1- carboxylate synthase (ACS) activity and (B) 1-aminocyclopropane-1-carboxylate oxidase (ACO) activity in leaves of cucumber seedlings after 3-d treatments. $\mathrm{C}=\mathrm{control}$; $\mathrm{CS}=\mathrm{control}+\mathrm{Spd}$ foliar spray; $\mathrm{S}=75 \mathrm{~mm} \mathrm{NaCl} ; \mathrm{SS}=75 \mathrm{~mm} \mathrm{NaCl}+$ Spd foliar spray. Values shown are means of three independent experiments. Different letters indicate significant differences (Duncan's multiple range test at $P<0.05$ ). 
Hoagland's solution and under salt stress. Expressions of acol and $a c o 2$ were somewhat downregulated by salt stress, whereas after application of exogenous Spd, their mRNA levels were increased (Fig. 4).

\section{Discussion}

Growth inhibition is one of the most common symptoms observed in plants subjected to environmental stress factors. According to our previous studies, exposure of cucumber seedlings to $\mathrm{NaCl}$ stress led to considerable declines in growth, whereas exogenous Spd alleviated the inhibition of plant biomass (Du et al., 2010; Duan et al., 2008).

Ethylene is a stress hormone involved in many stress responses. It regulates many aspects of the plant life cycle, including seed germination, root initiation, root hair development, flower development, sex determination, fruit ripening, senescence, and responses to biotic and abiotic stresses (Lin et al., 2009). Ethylene is produced by all cells during plant development, but the rates of production vary, with the highest rates being associated with meristematic, stressed, or ripening tissues. Although ethylene was believed to be the signaling molecule regulating the salt tolerance response activated by certain receptors such as ETR1, ETR2, ERS1, ERS2, and EIN4 (Cao et al., 2008), excessive ethylene production induced by salt stress can aggravate and inhibit plant growth. It has been suggested that many steps in ethylene biosynthesis are activated by abiotic stresses. For example, the rate of ethylene production dramatically increased under water deficit stress in excised wheat (Triticum aestivum) and was accompanied by increased levels of ACC and MACC (Hoffman et al., 1983). Hypoxia stress stimulated ACS activity and increased ACC levels and ethylene production rates (Wang and Arteca, 1992). The changes in ACC content, ACS and ACO activities, level of $A C S$ gene transcripts, and ethylene production were consistent in response to ultraviolet-B irradiation in tomato (Solanum lycopsicum) leaves (An et al., 2006). Our results also showed that ethylene production significantly increased in leaves of salt-stressed cucumber seedlings
(Fig. 1). We found that under salt stress, ACC synthesis and consumption were activated, together with increased activities of ACS and ACO, and there were higher levels of acs 2 transcripts (Fig. 4). In contrast, the expressions of the genes encoding ACO were slightly downregulated. These results indicate that $\mathrm{ACO}$ is not regulated at the transcriptional level in cucumber under salt stress but may be regulated at the post-translational level.

When exposed to various types of abiotic and biotic stresses, increased ethylene levels correspond to increased damage in plants, implying that stress-induced ethylene is deleterious to plants. Thus, many researchers have attempted to reduce ethylene production by various approaches. For example, coincubation with rhizobacteria containing ACC deaminase improved growth and nodulation in mung bean (Vigna radiata) under salt stress (Ahmad et al., 2011). Siddikee et al. (2011) found that rhizobacteria with ACC deaminase activity enhanced the growth and salt tolerance of red pepper (Capsicum annuum) seedlings by reducing salt stress-induced ethylene production. Wi et al. (2010) used transgenic tobacco (Nicotiana tabacum) expressing an antisense transcript of the ACC synthase gene, which inhibited ethylene production. This resulted in enhanced tolerance to abiotic stress and reduced accumulation of reactive oxygen species. Fuhrer et al. (1982) showed that exogenous spermidine inhibited ethylene biosynthesis and delayed senescence of oat (Avena sativa) leaves. The results of our study showed that application of exogenous Spd to salt-stressed cucumber seedlings resulted in decreased activity of ACS, decreased expression of acs 2 , and reduced levels of ACC. These results indicated that exogenous Spd significantly inhibited ACC synthesis under salt stress, which is consistent with the findings of Apelbaum et al. (1981) and Even-Chen et al. (1982), who also reported that polyamines inhibited ACC synthesis to decrease ethylene production. In addition, we observed that exogenous Spd downregulated expression of acs 2 under non-stress conditions (Fig. 4). This might be ascribed to regulation in transcription of some genes encoding ethylene biosynthetic enzymes by polyamines. In other studies, transgenic tomato overexpressing the spermidine
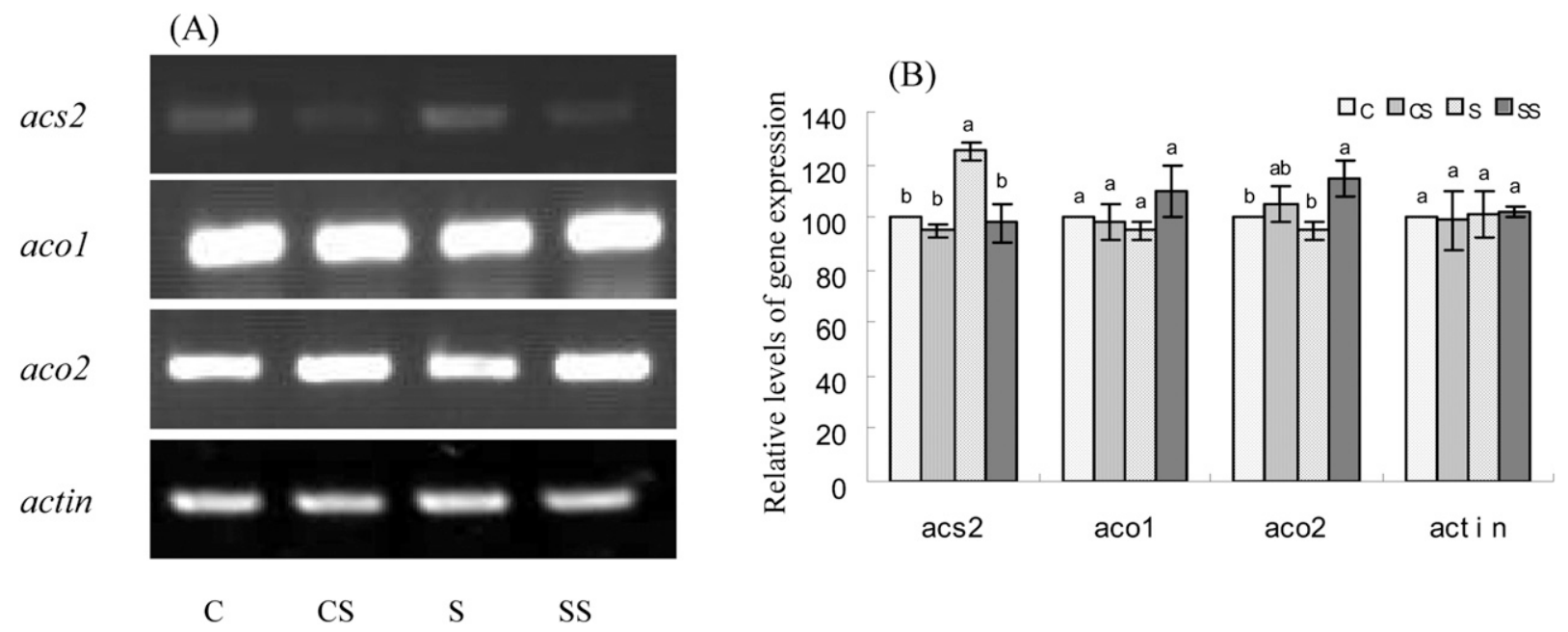

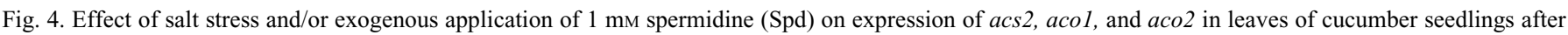
3-d treatments. $\mathrm{C}=$ control; $\mathrm{CS}=$ control + Spd foliar spray; $\mathrm{S}=75 \mathrm{~mm} \mathrm{NaCl} ; \mathrm{SS}=75 \mathrm{~mm} \mathrm{NaCl}+\mathrm{Spd}$ foliar spray. Transcript abundance was determined $(\mathbf{A})$, and the relative abundance ratio of genes was analyzed (B) using actin as the internal standard. Different letters indicate significant differences (Duncan's multiple range test at $P<0.05)$. 
synthase gene accumulated higher levels of Spd and showed downregulation of ACS gene transcripts (Handa et al., 2011; Nambeesan et al., 2012). According to our findings and the results of other studies, we conclude that exogenous Spd inhibits ACC synthesis, which is a crucial step in ethylene production.

Another point of regulation of ethylene production is the consumption of ACC. Some is converted into ethylene by $\mathrm{ACO}$, and some is conjugated to form MACC. In the present study, ACO activity and acol and aco 2 gene transcripts increased in response to Spd treatments of salt-stressed cucumber seedlings. Meanwhile, exogenous Spd reduced the MACC content in salt-stressed cucumber seedlings, indicating that it inhibited the conversion of ACC into MACC. We also found that exogenous Spd enhanced ACO activity and inhibited MACC accumulation under non-stress conditions. The ACO enzyme activity and gene activation were possibly regulated by $\mathrm{Ca}^{2+}$ and phosphoinositides in signal transduction pathway (Jung et al., 2000). In recent years, Spd-derived $\mathrm{H}_{2} \mathrm{O}_{2}$ has been identified as an important second messenger in signal transduction networks. Wu et al. (2010) found Spd induced an increase in the cytosolic $\mathrm{Ca}^{2+}$ concentration, which was exerted through a second messenger. Therefore, the increase of ACO activity and gene by Spd might be ascribed to Spd signal regulation. Although the conversion of ACO activity was enhanced by Spd under salt stress, ethylene emission was still lower than that under salt stress alone. We suggest that in the salt-stressed cucumber system, the inhibition of ethylene production by Spd was mainly through regulating ACS, the enzyme that catalyzes the rate-limiting step in ethylene production.

Higher PAs Spd and Spm biosynthesis and ethylene production used the same substrate SAM. Duan et al. (2008) found the activity of S-adenosylmethionine decarboxylase (SAMDC) was induced by $\mathrm{NaCl}$ stress in cucumber, indicating that the conversion of SAM to Spd and Spm was increased. Meanwhile, our results showed that the conversion of SAM to ACC was also increased under salt stress by the induction of ACS activity. However, the syntheses of PAs and ethylene are not competitive with each other in cucumber (Wang, 1987), so the conversion of SAM to PAs and ethylene might be independent under salt stress. Together with the result of Duan et al. (2008), exogenous Spd increased the level of endogenous PA biosynthesis and inhibited the conversion of SAM to ACC under salt stress, which might be the protective roles of exogenous PAs against the salt stress.

In conclusion, our results suggest that salt stress significantly increased the rate of ethylene production, which aggravated damage to plant growth. Application of exogenous Spd reversed the salt-induced ethylene production by inhibiting the transcription and activity of ACS. This indicated that exogenous Spd could modify ethylene biosynthesis to enhance the salt tolerance of cucumber seedlings.

\section{Literature Cited}

Ahmad, M., Z.A. Zahir, H.N. Asghar, and M. Asghar. 2011. Inducing salt tolerance in mung bean through coinoculation with rhizobia and plantgrowth-promoting rhizobacteria containing 1-aminocyclopropane-1carboxylate deaminase. Can. J. Microbiol. 57:578-589.

Alcazar, R., F. Marco, J.C. Cuevas, M. Patron, A. Ferrando, P. Carrasco, A.F. Tiburcio, and T. Altabella. 2006. Involvement of polyamines in plant response to abiotic stress. Biotechnol. Lett. 28:1867-1876.

An, L., X. Xu, H. Tang, M. Zhang, Z. Hou, Y. Liu, Z. Zhao, H. Feng, S. Xu, and X. Wang. 2006. Ethylene production and 1-aminocyclopropane-1-carboxylate (ACC) synthase gene expression in tomato (Lycopsicon esculentum Mill.) leaves under enhanced UV-B radiation. J. Integr. Plant Biol. 48:1190-1196.

Apelbaum, A., A.C. Burgoon, J.D. Anderson, and M. Lieberman. 1981. Polyamines inhibit biosynthesis of ethylene in higher plant tissue and fruit protoplasts. Plant Physiol. 68:453-456.

Bacilio, M., H. Rodriguez, M. Moreno, J.P. Hernandez, and Y. Bashan. 2004. Mitigation of salt stress in wheat seedlings by a gfp-tagged Azospirillum lipoferum. Biol. Fertil. Soils 40:188-193.

Bagni, N. and A. Tassoni. 2001. Biosynthesis, oxidation and conjugation of aliphatic polyamines in higher plants. Amino Acids 20:301-317.

Baysal, G. and R. Tipırdamaz. 2004. The effect of salinity on lipid peroxidation and some antioxidant enzyme activities in two cucumber cultivars. Acta Hort. 729:199-203.

Bouchereau, A., A. Aziz, F. Larher, and J. Martin-Tanguy. 1999. Polyamines and environmental challenges: Recent development. Plant Sci. 140:103-125.

Bradford, M.M. 1976. A rapid and sensitive method for the quantitation of microgram quantities of protein utilizing the principle of protein-dye binding. Anal. Biochem. 72:248-254.

Cao, Y.R., S.Y. Chen, and J.S. Zhang. 2008. Ethylene signaling regulates salt stress response: An overview. Plant Signal. Behav. 3:761-763.

Cheng, Z.C.Z., E.P.E. Park, and B.R.G.B.R. Glick. 2007. 1-Aminocyclopropane-1-carboxylate deaminase from Pseudomonas putida UW4 facilitates the growth of canola in the presence of salt. Can. J. Microbiol. 53:912-918.

Concepcion, M., C. Lizada, and S.F. Yang. 1979. A simple and sensitive assay for 1-aminocyclopropane-1-carboxylic acid. Anal. Biochem. 100:140-145.

Du, C.X., H.F. Fan, S.R. Guo, and T. Tezuka. 2010. Applying spermidine for differential responses of antioxidant enzymes in cucumber subjected to short-term salinity. J. Amer. Soc. Hort. Sci. $135: 18-24$.

Duan, J.J., J. Li, S.R. Guo, and Y. Kang. 2008. Exogenous spermidine affects polyamine metabolism in salinity-stressed Cucumis sativus roots and enhances short-term salinity tolerance. J. Plant Physiol. 165:1620-1635.

Even-Chen, Z., A.K. Mattoo, and R. Goren. 1982. Inhibition of ethylene biosynthesis by aminoethoxyvinylglycine and by polyamines shunts label from 3, 4-[14C] methionine into spermidine in aged orange peel discs. Plant Physiol. 69:385-388.

Fuhrer, J., R. Kaur-Sawhney, L.M. Shih, and A.W. Galston. 1982. Effects of exogenous 1,3-diaminopropane and spermidine on senescence of oat leaves: Inhibition of ethylene biosynthesis and possible mode of action. Plant Physiol. 70:1597-1600.

Galston, A.W. and R.K. Sawhney. 1990. Polyamines in plant physiology. Plant Physiol. 94:406-410.

Gamalero, E. and B.R. Glick. 2012. Ethylene and abiotic stress tolerance in plants, p. 395-412. In: Ahmad, P. and M.N.V. Prasad (eds.). Environmental adaptations and stress tolerance of plants in the era of climate change. Springer, New York, NY.

Handa, A., S. Nambeesan, T. Mengiste, K. Laluk, S. AbuQamar, and A. Mattoo. 2011. Polyamine spermidine is an upstream negator of ethylene-regulated pathogenesis of Botrytis cinerea in tomato leaf. Acta Hort. 914:109-112.

Hoffman, N.E., Y. Liu, and S.F. Yang. 1983. Changes in 1-(malonylamino) cyclopropane-1-carboxylic acid content in wilted wheat leaves in relation to their ethylene production rates and 1-aminocyclopropane1-carboxylic acid content. Planta 157:518-523.

Hoffman, N.E., S.F. Yang, A. Ichihara, and S. Sakamura. 1982. Stereospecific conversion of 1-aminocyclopropanecarboxylic acid to ethylene by plant tissues: Conversion of stereoisomers of 
1-amino-2-ethylcyclopropanecarboxylic Acid to 1-butene. Plant Physiol. 70:195-199.

Huang, S., R. Li, Z. Zhang, L. Li, X. Gu, W. Fan, W.J. Lucas, X. Wang, B. Xie, P. Ni, Y. Ren, H. Zhu, J. Li, K. Lin, W. Jin, Z. Fei, G. Li, J. Staub, A. Kilian, E.A.G. Vossen, Y. Wu, J. Guo, J. He, Z. Jia, Y. Ren, G. Tian, Y. Lu, J. Ruan, W. Qian, M. Wang, Q. Huang, B. Li, Z. Xuan, J. Cao, Asan, Z. Wu, J. Zhang, Q. Cai, Y. Bai, B. Zhao, Y. Han, Y. Li, X. Li, S. Wang, Q. Shi, S. Liu, W.K. Cho, J.Y. Kim, Y. Han, H.U. Katarzyna, H. Miao, Z. Cheng, S. Zhang, J. Wu, Y. Yang, H. Kang, M. Li, H. Liang, X. Ren, Z. Shi, M. Wen, M. Jian, H. Yang, G. Zhang, Z. Yang, R. Chen, S. Liu, J. Li, L. Ma, H. Liu, Y. Zhou, J. Zhao, X. Fang, G. Li, L. Fang, Y. Li, D. Liu, H. Zheng, Y. Zhang, N. Qin, Z. Li, G. Yang, S. Yang, L. Bolund, K. Kristiansen, H. Zheng, S. Li, X. Zhang, H. Yang, J. Wang, R. Sun, B. Zhang, S. Jiang, J. Wang, Y. Du, and S. Li. 2009. The genome of the cucumber, Cucumis sativus L. Nat. Genet. 41:1275-1281.

Jung, T., J. Lee, M. Cho, and W. Kim. 2000. Induction of 1-aminocyclopropane-1-carboxylate oxidase mRNA by ethylene in mung bean roots: Possible involvement of $\mathrm{Ca}^{2+}$ and phosphoinositides in ethylene signalling. Plant Cell Environ. 23:205-213.

Kato, M., Y. Hayakawa, H. Hyodo, Y. Ikoma, and M. Yano. 2000. Wound-induced ethylene synthesis and expression and formation of 1-aminocyclopropane-1-carboxylate (ACC) synthase, ACC oxidase, phenylalanine ammonia-lyase, and peroxidase in wounded mesocarp tissue of Cucurbita maxima. Plant Cell Physiol. 41:440-447.

Kato, M. and H. Hyodo. 1999. Purification and characterization of ACC oxidase and increase in its activity during ripening of pear fruit. J. Jpn. Soc. Hort. Sci. 68:551-557.

Kende, H. 1993. Ethylene biosynthesis. Annu. Rev. Plant Biol. 44:283-307.

Klassen, S.P.B. 2002. Sensitivity of wheat and rice to low levels of atmospheric ethylene. Crop Sci. 42:746-753.

Kumar, A., M. Taylor, T. Altabella, and A.F. Tiburcio. 1997. Recent advances in polyamine research. Trends Plant Sci. 2:124-130.

Kusano, T., T. Berberich, C. Tateda, and Y. Takahashi. 2008. Polyamines: Essential factors for growth and survival. Planta 228:367-381.

Lin, Z., S. Zhong, and D. Grierson. 2009. Recent advances in ethylene research. J. Expt. Bot. 60:3311-3336.

Malmberg, R.L., M.B. Watson, G.L. Galloway, and W. Yu. 1998. Molecular genetic analyses of plant polyamines. Crit. Rev. Plant Sci. 17:199-224.

Mathooko, F.M., Y. Kubo, A. Inaba, and R. Nakamura. 1995. Induction of ethylene biosynthesis and polyamine accumulation in cucumber fruit in response to carbon-dioxide stress. Postharvest Biol. Technol. 5:51-65.

Mayak, S., T. Tirosh, and B.R. Glick. 2004. Plant growth-promoting bacteria confer resistance in tomato plants to salt stress. Plant Physiol. Biochem. 42:565-572.

Moeder, W., C.S. Barry, A.A. Tauriainen, C. Betz, J. Tuomainen, M. Utriainen, D. Grierson, H. Sandermann, C. Langebartels, and
J. Kangasjarvi. 2002. Ethylene synthesis regulated by biphasic induction of 1-aminocyclopropane-1-carboxylic acid synthase and 1-aminocyclopropane-1-carboxylic acid oxidase genes is required for hydrogen peroxide accumulation and cell death in ozone-exposed tomato. Plant Physiol. 130:1918-1926.

Munns, R. and M. Tester. 2008. Mechanisms of salinity tolerance. Annu. Rev. Plant Biol. 59:651-681.

Nambeesan, S., S. Abuqamar, K. Laluk, A.K. Mattoo, M.V. Mickelbart, M.G. Ferruzzi, T. Mengiste, and A.K. Handa. 2012. Polyamines attenuate ethylene-mediated defense responses to abrogate resistance to botrytis cinerea in tomato. Plant Physiol. 158:1034-1045.

Penrose, D.M. and B.R. Glick. 2001. Levels of ACC and related compounds in exudate and extracts of canola seeds treated with ACC deaminase-containing plant growth-promoting bacteria. Can. J. Microbiol. 47:368-372.

Roberts, D.R., M.A. Walker, J.E. Thompson, and E.B. Dumbroff. 1984. The effects of inhibitors of polyamine and ethylene biosynthesis on senescence, ethylene production and polyamine levels in cut carnation flowers. Plant Cell Physiol. 25:315-322.

Siddikee, M.A., B.R. Glick, P.S. Chauhan, W. Yim, and T. Sa. 2011. Enhancement of growth and salt tolerance of red pepper seedlings (Capsicum annuum L.) by regulating stress ethylene synthesis with halotolerant bacteria containing 1-aminocyclopropane-1carboxylic acid deaminase activity. Plant Physiol. Biochem. 49:427434.

Slocum, R.D., R. Kaur-Sawhney, and A.W. Galston. 1984. The physiology and biochemistry of polyamines in plants. Arch. Biochem. Biophys. 235:283-303.

Walden, R., A. Cordeiro, and A.F. Tiburcio. 1997. Polyamines: Small molecules triggering pathways in plant growth and development. Plant Physiol. 113:1009-1013.

Wang, C.Y. 1987. Changes of polyamines and ethylene in cucumber seedlings in response to chilling stress. Physiol. Plant. 69:253 257.

Wang, T.W. and R.N. Arteca. 1992. Effects of low $\mathrm{O}_{2}$ root stress on ethylene biosynthesis in tomato plants (Lycopersicon esculentum Mill cv Heinz 1350). Plant Physiol. 98:97-100.

Wi, S.J., S.J. Jang, and K.Y. Park. 2010. Inhibition of biphasic ethylene production enhances tolerance to abiotic stress by reducing the accumulation of reactive oxygen species in Nicotiana tabacum. Mol. Cells 30:37-49.

Wu, J.Y., Z. Shang, X. Jiang, P.N. Moschou, W. Sun, K.A. RoubelakisAngelakis, and S.L. Zhang. 2010. Spermidine oxidase-derived $\mathrm{H}_{2} \mathrm{O}_{2}$ regulates pollen plasma membrane hyperpolarization-activated $\mathrm{Ca}^{2+}$ permeable channels and pollen tube growth. Plant J. 63:10421053.

Zahir, Z.A., U. Ghani, M. Naveed, S.M. Nadeem, and H.N. Asghar. 2009. Comparative effectiveness of Pseudomonas and Serratia sp. containing ACC-deaminase for improving growth and yield of wheat (Triticum aestivum L.) under salt-stressed conditions. Arch. Microbiol. 191:415-424. 